\title{
PREDICTOR PROPERTIES OF INDICATORS OF UNDIFFERENTIATED CONNECTIVE TISSUE DYSPLASIA IN CHILDREN WITH GASTROESOPHAGEAL REFLUX FOR PREDICTION OF THE DEVELOPMENT OF HEART RHYTHM AND CONDUCTION DISORDERS
}

\author{
Oksana Herasymova, Oksana Apanasenko
}

The aim: to improve the early diagnosis of cardiac arrhythmia and conduction disorders in children with gastroesophageal reflux by studying the predictor properties of indicators of undifferentiated connective tissue dysplasia in this category of patients.

Materials and methods. We examined 56 children aged 8 to 18 years, with an average age of $14.93 \pm 2.62$ years, of which 28 children with gastroesophageal reflux in combination with cardiac arrhythmias and conduction disorders were divided into group I, and 28 children with only gastroesophageal reflux without heart rhythm and conduction disturbances - into group II (control). All examined patients underwent clinical and instrumental studies (electrocardiography, 24-hour ECG Holter monitoring, esophagogastroduodenoscopy and PH-metry) and an assessment of the phenotypic signs of undifferentiated connective tissue dysplasia according to the criteria of T. Milkovskaya-Dimitrova and A. Karkashov.

Results. When analyzing the predictor properties of indicators of undifferentiated connective tissue dysplasia for predicting the development of cardiac arrhythmias and conduction disorders in children with gastroesophageal reflux, it was found that scoliotic posture had very high predictor properties (I=5.99), a high growth (I=1.94) and a short upper lip $(I=1.17)-$ high, dysplastic tooth growth (I=0 .6) - moderate, and an abnormal shape of the auricles - low ones $(I=0.27)$.

Other indicators of undifferentiated connective tissue dysplasia did not have predictive properties at all: joint hypermobility $(I=0.22)$, total number of signs of undifferentiated connective tissue dysplasia $(I=0.11)$, asthenic type of constitution $(I=0.11)$, flat feet $(I=0.08)$, refractive errors $(I=0.05)$, deviated septum of nose $(I=0.03)$, dilated bridge of the nose $(I=0.01)$, short neck $(I=0.01)$.

The mean value of the prognostic significance of indicators of undifferentiated connective tissue dysplasia was high $(\bar{I}=1.99)$.

Conclusions. It was found that the mean value of the prognostic significance of indicators of undifferentiated connective tissue dysplasia was high $(\bar{I}=1.99)$.

It was determined that arrhythmias and cardiac conduction disturbances in children with gastroesophageal reflux are associated with the presence of a scoliotic posture ( $I=5.99)$, high growth $(I=1.94)$, dysplastic growth of teeth $(I=0.6)$; in the absence of a short upper lip $(I=1.17)$ and an abnormal shape of the auricles $(I=0.27)$

Keywords: undifferentiated connective tissue dysplasia, gastroesophageal reflux, arrhythmias, children, predictor properties

How to cite:

Herasymova, O., Apanasenko, O. (2022). Predictor properties of indicators of undifferentiated connective tissue dysplasia in children with gastroesophageal reflux for prediction of the development of heart rhythm and conduction disorders. ScienceRise: Medical Science, 1 (46), 44-47. doi: http://doi.org/10.15587/2519-4798.2022.253073

(C) The Author(s) 2022

This is an open access article under the Creative Commons CC BY license hydrate

\section{Introduction}

An increasing medical problem is the increase in arrhythmias and conduction of the heart in children around the world $[1,2]$. The severity of the problem is due to the increased risk of malignant pathology and a large number of life-threatening complications [3, 4].

The clinical picture of arrhythmias and cardiac conduction disorders in childhood is often characterized by asymptomatic course or masking the symptoms of this pathological process under the symptoms of other pathologies, and therefore the diagnosis of this nosology causes difficulties for doctors $[5,6]$.
Differential diagnosis of arrhythmias and cardiac conduction disorders in combination with gastroesophageal reflux (GER) is also associated with many difficulties, as some digestive diseases (chronic gastroduodenitis) accompanied by GER are often asymptomatic; the second part (gastroesophageal reflux disease) is characterized by atypical cardiac symptoms that are similar to the clinical symptom complex of arrhythmias and conduction disorders. Even more difficult is the differential diagnosis of isolated variants of heart rhythm and conduction disorders in children with variants of its course in combination with GER [7,8]. 
An analysis of the scientific literature has shown that undifferentiated connective tissue dysplasia (UCTD) is a frequent predictor of cardiac arrhythmias and conduction. According to scientists, high mortality rates (more than 2,000 people every hour) from arrhythmias are observed in pediatric patients with signs of UCTD $[9,10]$.

However, the problem of determining the degree of prognostic value of UCTD in children for the development of cardiac arrhythmias and conduction in children with GER has not been sufficiently elucidated. Therefore, determining the predictor properties of UCTD signs for the prognosis of this pathology in children with GER will simplify its early diagnosis and differential diagnosis between it and isolated variants of arrhythmias and cardiac conduction disorders and digestive diseases accompanied by GER (gastroesophageal reflux disease and chronic gastroduodenitis), by developing an algorithm for early diagnosis of these disorders with the emphasis of doctors during the diagnostic process on the detection of signs of UCTD with greater prognostic value. This work is devoted to the study of these issues.

The aim of the work - to improve the early diagnosis of cardiac arrhythmias and conduction disorders in children with gastroesophageal reflux (GER) by studying the predictor properties of undifferentiated connective tissue dysplasia (UCTD) in this category of patients.

\section{Materials and methods}

We examined 56 children aged 8 to 18 years, with an average age of $14.93 \pm 2.62$ years, who were hospitalized on the basis of the city cardiorheumatology department of the "Children Clinical Hospital No. 24" of the Kharkiv City Council and dispensary supervision in the "City Children Clinic No. 23" Kharkiv City Council in the period from September 2018 to July 2021, of which 28 children with GER in combination with cardiac arrhythmias and conduction were divided into group I (main), and 28 children with only GER without cardiac arrhythmias and conductivity - in group II (control).

The distribution by sex was homogeneous in both groups: in group I - the number of boys was 18 (64.3 \pm 9.1 $\%)$ and girls $-10(35.7 \pm 9.1 \%)(\chi 2=0.571)$; in group II -12 $(42.9 \pm 9.4 \%)$ boys and $16(57.1 \pm 9.4 \%)$ girls $\left(\chi^{2}=2.286\right)$, respectively ( $\mathrm{p}>0.05)$.

During the study, the principles of the Helsinki Declaration adopted by the General Assembly of the World Medical Association (1964-2000) and the protocol of the Bioethics Commission of the "Kharkiv Medical Academy of Postgraduate Education" No. 3 dated 12.10.2021 were followed. Informed consent was obtained from all parents or guardians of children who participated in the study.

Criteria for inclusion in the study included:

1) the presence of GER in combination with cardiac arrhythmias and conduction or only GER without cardiac arrhythmias and conduction, 2) the age of children from 8 to 18 years, 3) voluntary consent of parents or guardians to participate in research.

Clinical studies have included surveys of patients on the presence or absence of relevant complaints that are characteristic of the studied pathology, nature, frequency, severity, duration and number of identified complaints.
Evaluation of UCTD phenotypic traits was performed according to the criteria of T. MilkovskaDimitrova and A. Karkashov.

The first degree - pronounced symptoms of UCTD, was assigned in the presence of the subject 5 main phenotypic features of UCTD and 3 secondary or more.

The second degree - moderate symptoms of UCTD, was determined by the presence of the child 3-4 major and 1-2 secondary phenotypic traits.

The third degree, which was a single symptom of UCTD, was characterized by the presence of 2 main phenotypic traits.

The presence or absence of major and minor phenotypic traits of UCTD was determined by examining and interviewing the patient.

Anamnestic studies were a detailed study of perinatal, hereditary history and life history and disease of patients.

The basis for confirming the presence of GER were the results of esophagogastroduodenoscopy.

Arrhythmias in children were verified using data obtained during electrocardiographic examination and Holter daily ECG monitoring with the Poly-spectrum DM device.

Exclusion criteria were congenital heart disease; acute inflammatory processes during the examination; condition after correction of congenital heart disease or radiofrequency catheter ablation; severe somatic pathology in a state of decompensation and refusal of parents of children or guardians to participate in the study.

Statistical processing of the results was performed using MS Office Excel (Microsoft Corporation, USA) and statistical online calculator epitools (epitools.ausvet.com.au, Austria). The age of patients was estimated by determining the sample mean and its standard error. Predictor properties of UCTD indicators were determined using the inhomogeneous Wald-Genkin sequential procedure, by calculating prognostic coefficients (PC) and informativeness (I). Homogeneity of groups by sex was checked on the basis of the criterion $\chi^{2}$ for one-dimensional frequency tables. All calculations were performed with a $95 \%$ confidence level.

\section{Research results}

A study of the predictor properties of UCTD indicators for predicting the development of cardiac arrhythmias and conduction in children with gastroesophageal reflux revealed (Tab. 1) that very high predictor properties are characteristic of scoliotic posture (I=5.99), and high - for high growth (I=1.94) and short upper lip (I=1.17).

Dysplastic growth of teeth is an indicator with moderate informativeness ( $\mathrm{I}=0.6)$.

In addition, it was found that the abnormal shape of the auricles had low predictor properties ( $\mathrm{I}=0.27)$.

Other indicators of undifferentiated connective tissue dysplasia had no predictive properties at all: hypermobility of joints $(\mathrm{I}=0.22)$, the total number of signs of undifferentiated connective tissue dysplasia $(\mathrm{I}=0.11)$, asthenic type of constitution ( $\mathrm{I}=0.11$ ), flat feet $\mathrm{I}=0.08$ ), refractive errors ( $\mathrm{I}=0.05)$, curvature of the nasal membrane ( $\mathrm{I}=0.03)$, enlarged nose $(\mathrm{I}=0.01)$, short neck $(\mathrm{I}=0.01)$. In general, the prognostic significance of indicators of undifferentiated connective tissue dysplasia was high ( $\overline{\mathrm{I}}=1.99)$. 
Table 1

Predictor properties of UCTD in patients with the development of cardiac arrhythmias and conduction in children with GER

\begin{tabular}{|c|c|c|c|}
\hline Indicators & Gradation of the indicator & ПК & I \\
\hline \multirow{2}{*}{ Scoliotic posture } & present & +6.36822 & \multirow[b]{2}{*}{5.993624} \\
\hline & absent & -10.414 & \\
\hline \multirow{2}{*}{ Tall } & present & +6.0206 & \multirow{2}{*}{1.935193} \\
\hline & absent & -3.0103 & \\
\hline \multirow{2}{*}{ Short upper lip } & present & -3.5218 & \multirow{2}{*}{1.166451} \\
\hline & absent & +3.0103 & \\
\hline \multirow{2}{*}{ Dysplastic tooth growth } & present & +1.76091 & \multirow{2}{*}{0.596402} \\
\hline & absent & -3.0103 & \\
\hline \multirow{2}{*}{ Abnormal shape of the auricles } & present & -3.0103 & \multirow{2}{*}{0.271579} \\
\hline & absent & +0.79181 & \\
\hline \multirow{2}{*}{ Hypermobility of joints } & present & -0.8715 & \multirow{2}{*}{0.220714} \\
\hline & absent & +2.21849 & \\
\hline \multirow{2}{*}{$\begin{array}{l}\text { The total number of signs of } \\
\text { UCTD }\end{array}$} & $\leq 5$ & -1.0474 & \multirow{2}{*}{0.11221645} \\
\hline & $\geq 6$ & +0 & \\
\hline \multirow{2}{*}{ Asthenic type of constitution } & present & +0 & \multirow{2}{*}{0.11221645} \\
\hline & absent & -1.0474 & \\
\hline \multirow{2}{*}{ Flatfoot } & present & +1.76091 & \multirow{2}{*}{0.076386} \\
\hline & absent & -0.3779 & \\
\hline \multirow{2}{*}{ Refraction anomalies } & present & -0.9691 & \multirow{2}{*}{0.050953} \\
\hline & absent & +0.45757 & \\
\hline \multirow{2}{*}{$\begin{array}{l}\text { Curvature of the nasal mem- } \\
\text { brane }\end{array}$} & present & -1.2494 & \multirow{2}{*}{0.025476} \\
\hline & absent & 0.17729 & \\
\hline \multirow{2}{*}{ Wide nose bridge } & present & +0 & \multirow{2}{*}{0.01149453} \\
\hline & absent & -0.3218 & \\
\hline \multirow{2}{*}{ Short neck } & present & +0 & \multirow{2}{*}{0.01149453} \\
\hline & absent & -0.3218 & \\
\hline
\end{tabular}

Note: the (+) sign indicates the development of heart rhythm and conduction disorders, and the (-) sign rejects the possibility of their occurrence

\section{Discussion}

According to the scientific literature, patients with arrhythmias, both in children and adults, are most often characterized by musculoskeletal and bone and joint signs of UCTD, namely: hypermobility of joints, posture disorders, abnormal changes in the dentition, asthenic body constitution, tall; somewhat less often in this category of patients could detect such signs of UCTD as: abnormalities in the development of the auricles, nasal dilation, refractive errors, etc. [11, 12].

In addition, high growth, scoliotic posture, and dysplastic tooth growth have been identified for UCTD, which are risk factors for arrhythmias in children with gastroesophageal disease.

No data on the signs of UCTD observed in arrhythmias in children with GER caused by other pathologies of the digestive system (chronic gastroduodenitis) have not been found.

There are also no data on the severity of the predictor properties of UCTD symptoms in children with GER to predict the development of cardiac arrhythmias and conduction.

The practical significance of the results of the study is to develop an algorithm for early diagnosis and differential diagnosis of arrhythmias and cardiac conduction disorders in combination with concomitant GER and isolated variants of this pathological process and diseases of the digestive system accompanied by
GER. The use of data from such an algorithm will help not only to increase the speed and accuracy of diagnosis, which in turn will reduce the number of dangerous complications and the risk of sudden death, characteristic of some forms of arrhythmias; but also will be profitable in economic terms, as it will reduce the financial costs of treatment of this pathology, due to its course in milder forms.

Study limitations: a small sample of patients participating in the study.

Prospects for further research: conducting research on a large sample of patients; study of information on the adequacy of the degree of heart rhythm and conduction in children with GER; as well as morphological lesions of the esophagus, stomach and duodenum in diseases of the digestive system, accompanied by GER (gastroesophageal reflux disease and chronic gastroduodenitis) - the frequency of phenotypic signs of UCTD and its severity in patients.

\section{Conclusions}

1. It was found that the average value of prognostic significance of undifferentiated connective tissue dysplasia was high $(\overline{\mathrm{I}}=1.99)$.

2. It was determined that arrhythmias and cardiac conduction disorders in children with gastroesophageal reflux are associated with: the presence of scoliotic posture $(\mathrm{I}=5.99)$, high growth $(\mathrm{I}=1.94)$, 
dysplastic tooth growth $(\mathrm{I}=0.6)$; and the absence of a short upper lip (I=1.17) and an abnormal shape of the auricles $(\mathrm{I}=0.27)$.

\section{Conflict of interests} interest.

\section{Funding}

The study was performed without financial support.

\section{Acknowledgments}

We express our gratitude to the patients who took part in the study, as well as the specialists who contributed to the investigation.

\section{References}

1. Blaufox, A. D. (2018). Irregular heart rhythm (arrhythmias) in children. Waltham.

2. Gonchar, M. O., Muratov, H. R., Strashok, O. I., Hain, M. A., Strelkova, M. I.; Senatorova, G. S. (Ed.) (2018). Takhiarytmii u ditei. Kharkiv, 84 .

3. Osteraas, N. (2021). Neurologic complications of brady-arrhythmias. Heart and Neurologic Disease. Elsevier, 163-174. doi: http://doi.org/10.1016/b978-0-12-819814-8.00006-8

4. Bagnall, R. D., Singer, E. S., Tfelt-Hansen, J. (2020). Sudden Cardiac Death in the Young. Heart, Lung and Circulation, 29 (4), 498-504. doi: http://doi.org/10.1016/j.hlc.2019.11.007

5. Drago, F., Battipaglia, I., Di Mambro, C. (2018). Neonatal and Pediatric Arrhythmias: clinical and electrocardiographic aspects. Cardiac Electrophysiology Clinics, 10 (2), 397-412. doi: http://doi.org/10.1016/j.ccep.2018.02.008

6. Rohit, M., Kasinadhuni, G. (2020). Management of Arrhythmias in Pediatric Emergency. The Indian Journal of Pediatrics, 87 (4), 295-304. doi: http://doi.org/10.1007/s12098-020-03267-2

7. Lakshmanadoss, U. (Ed.) (2020). Differential Diagnosis of Chest Pain. BoD-Books on Demand, 98. doi: http://doi.org/10.5772/intechopen.78875

8. Rees, C. J., Cantor, R. M., Pollack, Jr. C. V., Riese, V. G.; Pollack, Jr. C. (Ed.) (2019). Gastroesophageal Reflux Disease. Differential Diagnosis of Cardiopulmonary Disease. Cham: Springer, 441-449. doi: http://doi.org/10.1007/978-3-319-63895-9_30

9. Lukianenko, N. S., Petritsa, N. A., Kens, K. A. (2015). Place of undifferentiated connective tissue dysplasia in childhood pathology (literature review). Zdorove rebenka, 2, 80-85. Available at: http://nbuv.gov.ua/UJRN/Zd_2015_2_18

10. Zikriyaevna, S. G. (2017). Special features of clinical and functional disorders in patients with undifferentiated connective tissue dysplasia. European science review, 3-4, 72-74.

11. Yagoda, A. V., Novikova, M. V., Gladkikh, N. N. (2015). Faktory riska prognosticheski znachimykh narusheniy serdechnogo ritma pri displazii soedinitelnoy tkani. Arkhiv vnutrenney meditsiny, 1, 60-63.

12. Herasymova, O., Filonova, T. (2021). Undifferentiated connective tissue dysplasia as a predictor of heart rate disorders in combination with gastroesophageal reflux disease in children. ScienceRise: Medical Science, 4 (43), 41-45. doi: http://doi.org/10.15587/2519-4798.2021.238132

Received date 01.11.2021

Accepted date 16.12.2021

Published date 30.01.2022

Oksana Herasymova*, Postgraduate Student, Department of Pediatrics and Pediatric Cardio-Rheumatology, Kharkiv Medical Academy of Postgraduate Education, Amosova str., 58, Kharkiv, Ukraine, 61176

Oksana Apanasenko, PhD, Assistant, Department of Pediatrics and Pediatric Cardio-Rheumatology, Kharkiv Medical Academy of Postgraduate Education, Amosova str., 58, Kharkiv, Ukraine, 61176

*Corresponding author: Oksana Herasymova, e-mail: oleksiisenik@ukr.net 